\title{
Formation and Disappearance of Thermal Stratification in a Small Shallow Lake
}

\section{Lap, Bui Quoc}

Researcher at Department of Bioproduction and Bioenvironment Sciences, Graduate School of Bioresource and Bioenvironmental Sciences, Kyushu University

\section{Tuan, Nguyen Van}

Laboratory of Bioproduction and Environment Information Sciences, Division of Bioproduction and Environment Information Sciences, Department of Bioproduction and Bioenvironment Sciences, Graduate School of Bioresource and Bioenvironmental Sciences, Kyushu University

\section{Hamagami, Kunihiko}

Laboratory of Bioproduction and Environment Information Sciences, Division of Bioproduction and Environment Information Sciences, Department of Bioproduction and Bioenvironment Sciences, Graduate School of Bioresource and Bioenvironmental Sciences, Kyushu University

\section{Iguchi, Shota}

Laboratory of Bioproduction and Environment Information Sciences, Division of Bioproduction and Environment Information Sciences, Department of Bioproduction and Bioenvironment Sciences, Graduate School of Bioresource and Bioenvironmental Sciences, Kyushu University

他

https://doi.org/10.5109/14069

出版情報：九州大学大学院農学研究院紀要. 54 (1)，pp. 251-259，2009-02-27. Faculty of Agriculture, Kyushu University

バージョン :

権利関係 : 


\title{
Formation and Disappearance of Thermal Stratification in a Small Shallow Lake
}

\section{Bui Quoc LAP ${ }^{1}$, Nguyen Van TUAN ${ }^{2}$, Kunihiko HAMAGAMI ${ }^{2}$, Shota IGUCHI ${ }^{2}$, Ken MORI* and Yasumaru HIRAI}

\author{
Laboratory of Bioproduction and Environment Information Sciences, Division of Bioproduction and \\ Environment Information Sciences, Department of Bioproduction and Environment Science, \\ Faculty of Agriculture, Kyushu University, Fukuoka 812-8581, Japan \\ (Received November 14, 2008 and accepted December 5, 2008)
}

\begin{abstract}
In closed water bodies which the inflow and outflow are usually small, vertical transportation based on the formation of water temperature stratification, the problem of water quality pollution due to the inhibition of mixing easily occur, especially the problems become serious in shallow water bodies. The main reasons that drive the formation and disappearance of water temperature stratification are mechanical disturbance caused by the acting of wind, or solar radiation in daytime, thermal disturbance due to radiational cooling at night. Clarifying the processes of formation and disappearance of stratification response to these two kinds of disturbance is very important for management and improvement of the environment in the water bodies. So, in this research, a shallow closed water body with the overgrowth of aquatic plants was targeted for field observation and quantitative discussion on the processes of formation and disappearance of the thermal stratification.
\end{abstract}

\section{INTRODUCTION}

The results of field observation (meteorological data, water temperature...) show that in the case of strong solar radiation and weak wind, thermal stratification exists, when solar radiation is weak and wind is strong, thermal stratification will disappear. In addition, the prevalence of thermal stratification also impacts on the results of water quality observation.

In other words, the impact of thermal stratification which causes the deterioration of water quality is especially large in summer (Lap et al., 2006). The amount of movement and the vertical transportation of substances between top and bottom layers were inhibited by the thermal stratification, when this condition takes long time, it becomes bad to water quality in the water body.

More specifically, due to the daily movement of the formation and disappearance of the thermal stratification, as mixing layer is not developed, stratification exists, the existence of discontinuity layer gives large impacts to the water quality environment of the water body (Mori et al., 2001).

Consequently, it is very important to make clear the processes of the formation and disappearance of thermal stratification driven by thermal convection due to the heat release from the water surface at night in temperature-stratified positions formulated by daily solar radiation, and the wind-induced flow driven by the acting of wind on the water surface in closed water bodies (Mori

Researcher at Department of Bioproduction and Bioenvironment Sciences, Graduate School of Bioresource and Bioenvironmental Sciences, Kyushu University

Laboratory of Bioproduction and Environment Information Sciences, Division of Bioproduction and Environment Information Sciences, Department of Bioproduction and Bioenvironment Sciences, Graduate School of Bioresource and Bioenvironmental Sciences, Kyushu University

* Corresponding author (E-mail: moriken@bpes.kyushu-u.ac.jp) et al., 2001; Lap and Mori, 2007). The magnitude of formation and disappearance of thermal stratification is closely related to the amount of solar radiation, windinduced flow and the scale of thermal convection. More specifically, it strongly depends on wind stress acting on the water surface as well as the added amount of heat, the heat release from the water surface.

\section{MATERIALS AND METHODS}

\section{Study area}

Field observation was done in an agricultural pond (the Shikinawa Pond) located in Kasuya Town, Fukuoka Prefecture during a 24-hour period. The area of the pond is about $4.93 \mathrm{ha}$, the deepest depth is $5 \mathrm{~m}$, part of bank protection paved by concrete.

During observation, there were nearly not the inflow and outflow, without the change of water level. In other words, it is thought that the variation of water quality in this water body was dominated by only biological and physical disturbances.

\section{Field observation method}

Measured items are meteorological parameters such as air temperature, humidity, wind velocity, wind direction and solar radiation, water quality parameters including water temperature, dissolved oxygen and $\mathrm{pH}$. Measured items and equipments are shown in Table 1. Measurement method of each item was inscribed below. Meteorological parameters

Meteorological apparatus was set on the water surface of the lake. Solar radiation sensors 1, 2 were set at $15 \mathrm{~cm}$ above the water surface, the sensor 1 measured the quantity of absorbed solar radiation, the sensor 2 measured the reflecting solar radiation. Each set of wind velocity, wind direction and humidity sensors was set at $50 \mathrm{~cm}, 150 \mathrm{~cm}$ above the water surface, respectively. Midi logger (GL-800-UM-102, GRAPHTEC) was used 


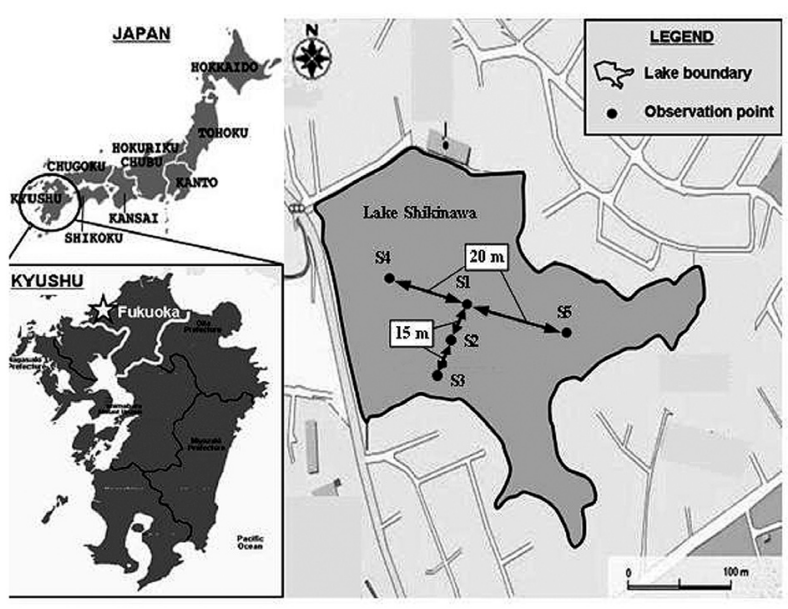

Fig. 1. Location of Lake Shikinawa and observation points.

Table 1. Main characteristics of Lake Shikinawa

\begin{tabular}{lll}
\hline Characteristic & Unit & Value \\
\hline Basin area & ha & 25.8 \\
Water surface area & ha & 4.93 \\
Total volume & $\mathrm{m}^{3}$ & 123,000 \\
Effective volume & $\mathrm{m}^{3}$ & 123,000 \\
Average depth & $\mathrm{m}$ & 2.5 \\
Maximum length & $\mathrm{m}$ & 350 \\
Maximum width & $\mathrm{m}$ & 175 \\
\hline
\end{tabular}

for data recording at every 1 minute.

Vertical distribution of water temperature

Measurement of vertical distribution of water temperature used a tool of water temperature measurement which thermocouple was set in PVC pipe. Measurement was done at $11-15$ points with $20 \mathrm{~cm}$ interval from the water surface in the vertical direction, at every 1 minute, with the using of Thermodak EF (5020A, Etou electrical Co., Ltd.) for data recording. Besides, multi-sensors (W-23XD, Horiba company (Co., Ltd.) was used to measure at every $50 \mathrm{~cm}$ vertically.

Observation condition

Observation was implemented two times in Shikinawa Lake, Kasuya Town as follows

The first time : from 5:00 pm August 7 to 4:00 pm August 8,2007
The second time : from 9:00 am November 21 to 8:00 am November 22, 2007

The observation was set up at 5 points from St.1 to St.5. The observation points were shown in Fig. 1. In the first time observation, floating leaf plants (water chestnut) covered about 1/3 of the water surface, St.2 was set at the boundary with the area of floating leaf plants, St.3 was in the area of the floating leaf plants. In the second time, the observation was done at the same positions with the first time but without the coverage of floating leaf plants.

\section{RESULTS AND DISCUSSION}

\section{Effects of thermal convection and wind-induced flow to the development of mixing layer}

Due to the wind-induced flow based on wind stress acting on the water surface, and the action of the thermal convection caused by the heat release from the water surface, turbulent flow in the mixing layer develops and the effects of each case in which the thickness of the mixing layer develops was considered.

Now, assuming that water temperature in the mixing layer is $T$, the mixing layer thickness is $h$, water temperature difference between the mixing layer and the bottom layer (from the under bed of the mixing layer to the base) is $\Delta T$, differential density is $\Delta \rho$ the density of the bottom layer is $\rho_{0}$, coefficient of thermal expansion of water $\alpha$ can be expressed as follows.

$$
\alpha=-\left(1 / \rho_{0}\right)(\Delta \rho / \Delta T)
$$

The original point of coordinate axes was set at the water surface of the water body, $x, y$ were set on the water surface, $z$ axis is downward vertically, flow velocities in the $x, y, z$ directions are $u, v, w$, respectively, that magnitude is $q$, pressure, variation of density due to turbulence are $p, p^{\prime}$, respectively, the energy balance equation at the boundary of discontinuity layer (the under bed of mixing layer) is

$$
\frac{\partial}{\partial t} \overline{q^{2}}+\frac{\partial}{\partial z} \overline{w\left(\frac{p}{p_{0}}+q^{2}\right)}=\alpha g \overline{(w T)}-\varepsilon
$$

where $\varepsilon$ is energy dissipation. The terms with over-bar express the time-averaged values.

Now, using velocity scale $\sigma$ in each item of the above

\begin{tabular}{|c|c|c|c|}
\hline Measured items & Equipments & Measured points & Interval (minute) \\
\hline Water temperature & Multi-sensor probe (W-23XD, Horiba company (Co.,Ltd.)) & 5,6 & $\begin{array}{l}\text { Daytime : } 180 \\
\text { Night : } 240\end{array}$ \\
\hline Water temperature & Thermocouple ( $\phi 0.3 \mathrm{~mm} \mathrm{C}-\mathrm{C}$ line $)$ & $11 \sim 15$ & 1 \\
\hline Solar radiation & $\begin{array}{l}\text { Solar radiation sensor (IKS-37-10, Koito Industries, Limited) } \\
\text { Wind velocity sensor }\end{array}$ & 2 & 1 \\
\hline Wind velocity & $\begin{array}{l}\text { (MES-1307/A702, Koito Industries, Limited) } \\
\text { Wind direction sensor }\end{array}$ & 2 & 1 \\
\hline Wind direction & $\begin{array}{l}\text { (MES-1306/A802, Koito Industries, Limited) } \\
\text { Temperature, humidity sensors }\end{array}$ & 2 & 1 \\
\hline Humidity and air temperature & (MES-1101B-10, Koito Industries, Limited) & 2 & 1 \\
\hline
\end{tabular}

Table 2. List of Measured Items and Equipments 
equation gives

The first left side item

$$
\frac{\partial}{\partial t} \overline{q^{2}}=-\frac{\partial}{\partial z} \overline{q^{2}} \frac{\partial h}{\partial t}=C_{T} \frac{\sigma^{2}}{h} \frac{\partial h}{\partial t}
$$

The second left side item

$$
\frac{\partial}{\partial z} \overline{w\left(\frac{p}{\rho_{0}}+q^{2}\right)}=-C_{F} \frac{\sigma^{3}}{h}
$$

The first right-side item

$$
\alpha g \overline{(w T)}=-\frac{g \Delta \rho}{\rho_{0}} \frac{\partial h}{\partial t}
$$

The second right-side item

$$
\varepsilon=C_{D} \sigma^{2}\left(\frac{g \Gamma}{\rho_{0}}\right)^{\frac{1}{2}}
$$

where, $h$ is the thickness of the mixing layer, $\partial h / \partial t$ expresses the speed of mixing development. $\Gamma$ is density gradient of the water body before the formation of mixing layer. and, $C_{T}, C_{F}, C_{D}$ are constant.

Firstly, when stratification is strong and the thickness of the mixing layer is thin, because the first left-side item and the second right-side item are approximately neglected compared to other items, the second left-side item and the first right-side item become equal, namely,

$$
\frac{1}{\sigma} \frac{\partial h}{\partial t} \propto \frac{\rho_{0} \sigma^{2}}{\Delta \rho g h}=\frac{1}{R_{i}}
$$

Where, $R_{i}=g \Delta \rho h / \rho_{0} \sigma^{2}$ is Richardson number. The above equation indicates that development speed of the mixing layer is inversely proportional to Richardson number.

Secondly, in the case of weak stratification and thick discontinuity layer, all items are taken into consideration. It means

$$
C_{T} \frac{\sigma^{2}}{h} \frac{\partial h}{\partial t}-C_{F} \frac{\sigma^{3}}{h}=-\frac{g \Delta \rho}{\rho_{0}} \frac{\partial h}{\partial t}-C_{D} \sigma^{2}\left(\frac{g \Gamma}{\rho_{0}}\right)^{\frac{1}{2}}
$$

Using Richardson number mentioned above, the above equation takes the form as follows

$$
\frac{1}{\sigma} \frac{\partial h}{\partial t}=\frac{C_{F}-C_{D}\left(2 R_{i}\right)^{\frac{1}{2}}}{C_{t}+R_{i}}
$$

Equations (6) and (8) indicate that the development speed of mixing layer was expressed as a function of Richardson number which used velocity scale $\sigma$.

Now, the main causes of turbulent mixing of mixing layer in closed water bodies are the wind-induced flow and the thermal convection, this case of velocity scale, water friction velocity $u_{*}$ and convection velocity $w_{c}$ can be used, respectively.

Consequently, the development speed of mixing layer in closed water bodies, that is, disappearance process of thermal stratification can be expressed as a function of Richardson number using velocity scale $u_{*}, w_{c}$.

In the case that wind-induced flow is the dominant cause of turbulent mixing in the mixing layer, accordingly from (6) water friction velocity $u_{*}$ as velocity scale in equation (8) can be gotten, in the case of thermal convection, convection velocity $w_{c}$ can be taken. Furthermore, in the case that the contributions of windinduced flow and thermal convection are equal, velocity scale $\sigma$ can be shown in the below equation as a harmony of each action.

$$
\sigma=\left(u_{*}^{3}+w_{c}^{3}\right)^{\frac{1}{3}}
$$

Water friction velocity $\boldsymbol{u}_{*}$ and convection velocity $\boldsymbol{w}_{\boldsymbol{c}}$

When wind velocity distribution acting on the water surface is logarithmic distribution, the below logarithmic rule is established.

$$
\frac{U(z)}{u_{*_{a}}}=\frac{1}{\kappa} \ln \frac{z}{z_{0}}
$$

Where, $U(z)$ is wind velocity at the height of $z$ from the water surface, $u_{*_{a}}$ is air friction velocity, $z_{0}$ is roughness coefficient, $\kappa$ is Karman constant. If wind velocities $U\left(z_{1}\right), U\left(z_{2}\right)$ at the height $z_{1}, z_{2}\left(z_{2}>z_{1}\right)$ from the water surface are measured, air friction velocity can be drawn from the above equation as follows

$$
u_{*_{a}}=\frac{U\left(z_{2}\right)-U\left(z_{1}\right)}{\frac{1}{\kappa} \ln \frac{z_{2}}{z_{1}}}
$$

If assuming that air shear stress $\tau_{a}$ acting on the water surface due to the action of wind and water shear stress $\tau_{w}$ on the water surface of the wind-induced flow are continuous, it gives

$$
\begin{aligned}
& \tau_{a}=\rho_{a} u_{*}{ }^{2} \\
& \tau_{w}=\rho_{w} u_{*}{ }^{2}
\end{aligned}
$$

then, water friction velocity which is velocity scale of wind-induced flow can be calculated as follows.

$$
u_{*}=\left(\frac{\rho_{a}}{\rho_{w}}\right)^{\frac{1}{2}} u_{* a}
$$

where, $\rho_{a}, \rho_{w}$ are air and water of densities, respectively. When there are no values of wind velocities at 2 elevations, in this case, wind velocity $U_{10}$ at $10 \mathrm{~m}$ above the water surface can be used, water shear stress $\tau_{w}$ at the water surface of the wind-induced flow can be calculated below.

In the case of smooth water surface,

$$
\tau_{w}=0.8 \times 10^{-3} \rho_{a} U_{10}^{2}
$$

When the water surface is rough,

$$
\tau_{w}=2.6 \times 10^{-3} \rho_{a} U_{10}^{2}
$$

Whether the water surface is smooth or rough depends on the value of wind speed, critical wind speed is $6.6 \mathrm{~m} / \mathrm{s}$.

Using the speed of water temperature degradation in the mixing layer and average speed of horizontal convection to attempt to estimate the development speed of mixing layer. In vertical one-dimensional water temperature conservation equation in the mixing layer, assuming that transportation based on convection flow caused by uncertain density is large compared to the transporta- 
tion due to diffusion, the below equation can be drawn.

$$
\frac{\partial T}{\partial t}=-\frac{\partial}{\partial z}\left(w_{f} \hat{T}\right)
$$

where, $w_{f}$ is horizontally averaged settling velocity of convection mass, $\hat{T}$ indicates the difference between cold water mass of water temperature $T_{w}$ and temperature of the surrounding water $T$.

If integrating the above equation from $z=0$ to $h$ in the mixing layer, it gives

$$
h \frac{d T}{d t}=-\left\{\left(w_{f} \hat{T}\right)_{h_{1}}-\left(w_{f} \hat{T}\right)_{0}\right\}
$$

The following boundary condition was assumed

$$
z=0 ;\left(w_{f} \hat{T}\right)_{0}=-\frac{Q}{\rho c_{P}}
$$

$w_{f}(h)$ was arranged as follows

$$
w_{f}(h)=-\frac{1}{\hat{T}(h)}\left(h \frac{d T}{d t}+\frac{Q}{\rho c_{P}}\right)
$$

Then, if motion energy of velocity $w_{f}\left(h_{1}\right)$ of convection mass at the neighborhood of discontinuity layer was transformed into potential energy, energy balance is expressed in the following equation.

$$
\frac{1}{2} w_{f}^{2}(h)=\alpha \hat{T}(h) g h
$$

then, velocity of convection mass at discontinuity layer interface becomes

$$
w_{f}(h)=\left\{-2 \alpha g h\left(\frac{Q}{\rho c_{P}}\right)\right\}^{\frac{1}{3}}
$$

\section{Investigation on the formation and disappearance of thermal stratification by field observation}

Based on meteorological elements (wind velocity, air temperature, solar radiation) and observed results of water temperature, the formation and disappearance of thermal stratification in Shikinawa Lake was observed to discuss.

Figs. 2 and $\mathbf{3}$ indicate the results figuring out information necessary for discussion based on the fieldobserved results. Also, water friction velocity $u_{*}$ which is velocity scale of wind-induced flow was calculated by the above equation (11) and (12) using wind velocities at 2 elevations. Convection flow velocity $w_{c}$ which is velocity scale of thermal convection flow was calculated by the above equation (18). Additionally, heat quantity and temporal change of potential energy were calculated as potential energy and heat quantity that there is water column of unit area from water surface to the bottom, using the vertical distribution of water temperature at every measured time. Furthermore, heat flux at the water surface was calculated from the temporal change of heat quantity.

In general, thermal stratification formed by daytime solar radiation strongly depends on the magnitude of
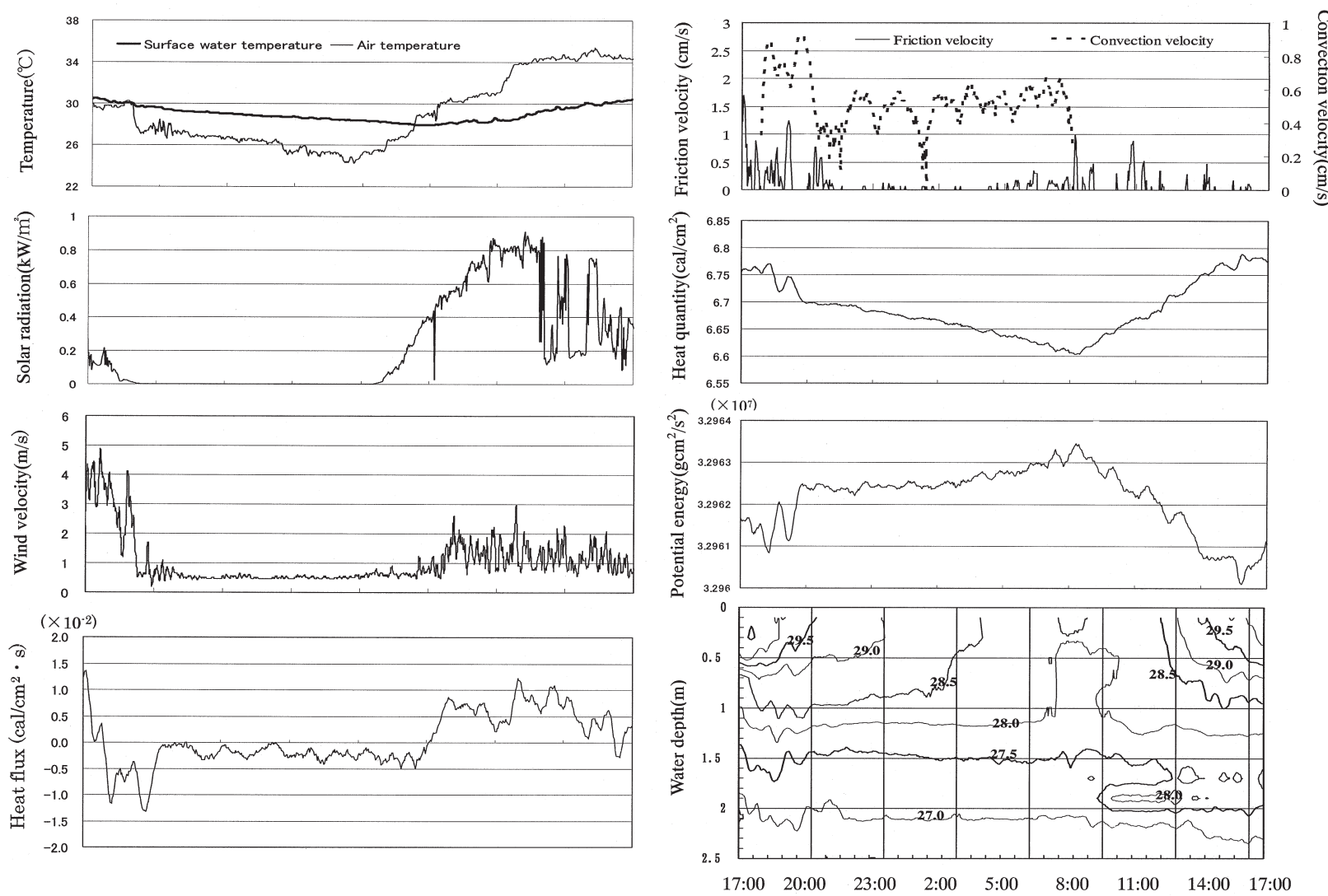

Fig. 2. The first time observation of air temperature, surface water temperature, absorbed solar radiation, wind velocity, the temporal change of heat flux, friction velocity, heat quantity, temporal change of potential energy and isothermal diagram. 

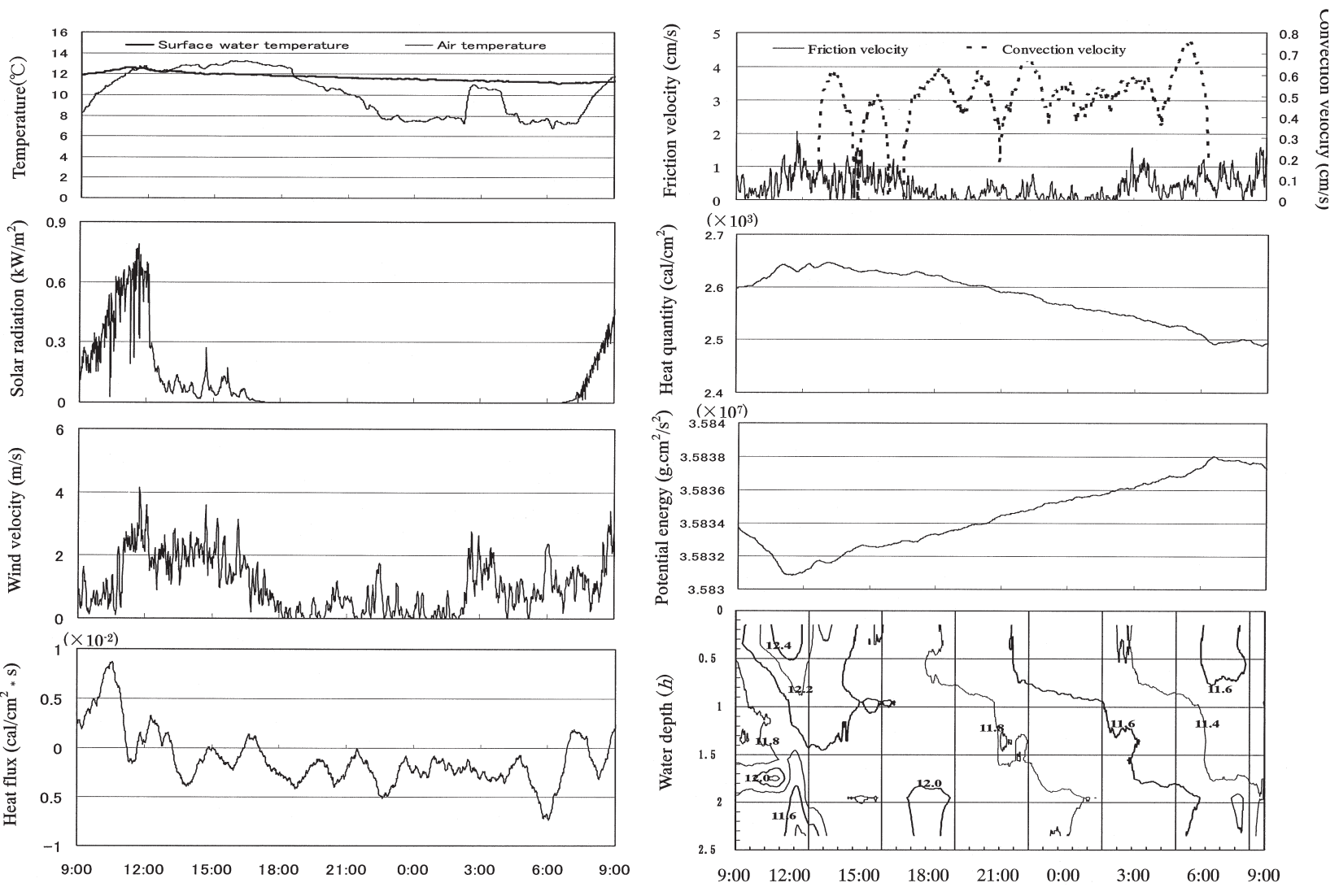

Fig. 3. The second time of observation of air temperature, surface water temperature, absorbed solar radiation, wind velocity and the temporal change of heat flux, friction velocity, heat quantity, temporal change of potential energy and isothermal diagram.

thermal convection based on heat emission from the water surface and the wind-induced flow caused by the action of wind. More specifically, velocity scale of windinduced flow $u_{*}$ is closely related to the amplitude of velocity scale of thermal convection $w_{c}$. In addition, in the period of heat release, most commonly $w_{c}>u_{*}$, the impact of thermal convection to the turbulent mixing of water temperature stratification field is large compared to the impact of wind-induced flow based on the action of wind. In the period of heat receiving, because temperature stratification field based on significant water temperature of surface layer is greatly stable, there is no thermal convection, it is regarded as $w_{c}=0$.

Firstly, discussing about the formation and disappearance of thermal stratification in Shikinawa Lake in the first observation of August.

In Fig. 2, the temporal change of air temperature and surface layer water temperature after sunset from about 18:30 to 7:00 of next morning, surface water temperature is $3{ }^{\circ} \mathrm{C}$ to $5^{\circ} \mathrm{C}$ higher than air temperature, this period contributes to the disappearance of thermal stratification, the formation and development of mixing layer based on thermal convection due to heat emission. It can be seen the temporal change of absorbed solar radiation quantity because from sunrise of 6:00 am solar radiation steadily arises. It can be seen that after the highest solar radiation period of 13:00 solar radiation decreased because of the cloud appearance, however, nearly sufficient solar radiation was added to the water surface.
The temporal change of wind velocity was shown that just after the start of observation from 5:00 pm within about 2.5 hours, the average wind velocity is $3.5 \mathrm{~m} / \mathrm{s}$. During this period, thermal convection nearly did not take place, the ague of formation and development of mixing layer due to wind-induced flow, contributing to the disappearance process of thermal stratification. And, wind velocity of $0.5 \mathrm{~m} / \mathrm{s}$ continued from 8:00 pm to the time of solar radiation start of next morning. In this period, the disappearance process of thermal stratification is almost due to thermal convection, there is no contribution from the wind-induced flow. In the next day, after 2 hours from the solar radiation start daily wind started blowing, the average speed of $1.2 \sim 1.5 \mathrm{~m} / \mathrm{s}$ continued to the sunset. This period is the significant water temperature stratification process due to the strong solar radiation in the midst of summer, but owing to the blowing of wind, stratification intensity of surface layer is considered to be slightly weak.

Velocity scales $u_{*}, w_{c}$ in Fig. 2, firstly, just after observation start $u_{*}=1.5 \mathrm{~cm} / \mathrm{s}$ can be seen, after that within 3 hours, it fluctuated between $0.5 \sim 1 \mathrm{~cm} / \mathrm{s}$. And, the period of time in which thermal convection at night was predominant, it is nearly 0 , in the next day, based on the daily wind and solar radiation, it underwent at the amplitude of $0.5 \mathrm{~cm} / \mathrm{s}$. Next, after sunset a few hours $w_{c}$ fluctuated at $0.6 \sim 0.9 \mathrm{~cm} / \mathrm{s}$, after that to solar radiation start, it fluctuated at $0.4 \sim 0.7 \mathrm{~m} / \mathrm{s}$.

Moreover, in the first time of observation, in order to 
understand from the temporal change of potential energy and isothermal diagram, from 1 hour after observation start the development of mixing layer, in other words, the disappearance process of thermal stratification began, this process continued to 8:00 am of next day.

So, if the temporal change of potential energy of this period is seen in detail, 3 time slots which those change rates were different can be classified. More specifically, there are 3 regions, namely, after 1 hour just from observation start, the time slot of 3 -hour length (sphere I), after this time-slot to about 6:00 am of solar radiation start of the next morning is the time-slot II (sphere II), after the time-slot II to about 8:00 is the time-slot III (sphere III). Sphere I is the time-slot which windinduced flow was predominant, the increased rate of potential energy is highest. Following is the increased rate of sphere III of potential energy that took the second place. This time-slot was also weak, but was the period which wind-induced flow was large in scale compared to thermal convection. The increment rate of the potential energy of sphere II was smallest. This timeslot was the period which thermal convection was predominant, there was nearly no the action of wind. Based on Fig. 4 describing the temporal change of vertical distribution of water temperature, the rate change of the mixing layer thickness was calculated, attempting evaluation of the contribution to the disappearance process of thermal stratification of thermal convection and windinduced flow.

In the result, $\partial h / \partial t=0.12 \mathrm{~m} / \mathrm{h}, 0.033 \mathrm{~m} / \mathrm{h}$ and $0.05 \mathrm{~m} / \mathrm{h}$ in spheres I, II and III, respectively. In the dis-
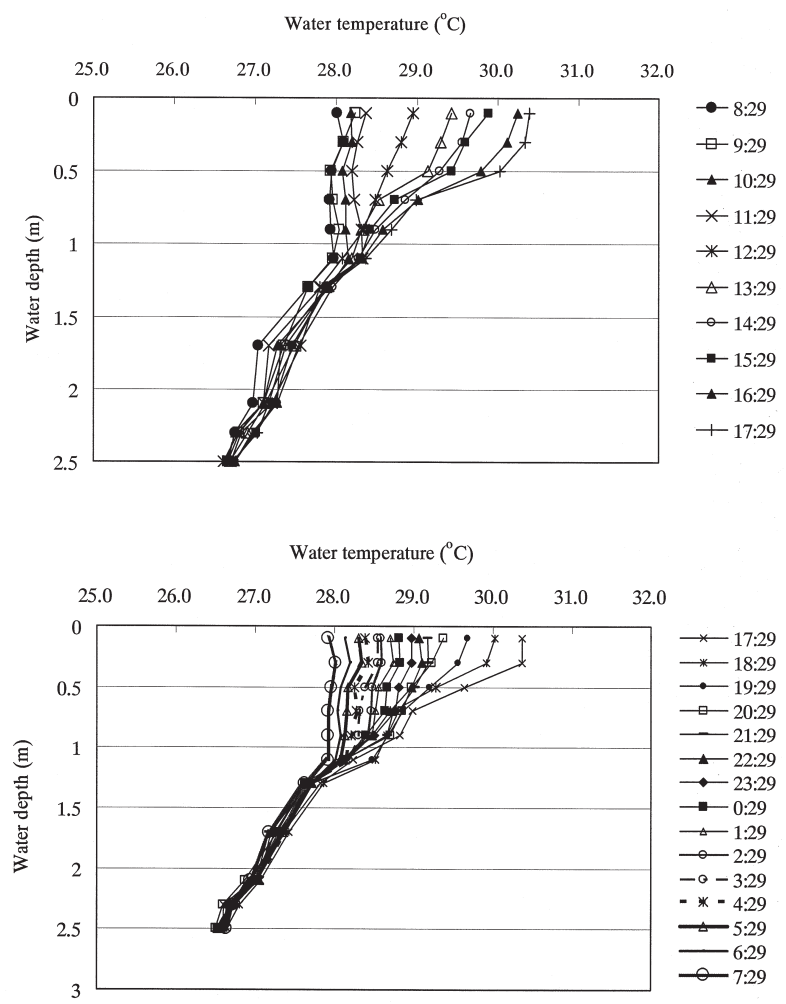

Fig. 4. Temporal variation of vertical distribution of water temperature at $\mathrm{S} 2\left(1^{\text {st }}\right.$. Obs.). appearance process of thermal stratification of Shikinawa Lake in August, in the case of wind speed $=3.5 \mathrm{~m} / \mathrm{s}$, the increment rate of mixing layer thickness in the meantime was about four times higher than that of the mixing layer thickness based on the thermal convection due to the difference of $3 \sim 5{ }^{\circ} \mathrm{C}$ between air temperature and water temperature of surface layer at night.

Regarding to the second time of observation in November, vertical distribution of water temperature at the time of starting observation was nearly homogeneous, and from Fig. 5, diurnal stratification was also weak, because thermal stratification was nonexistent, it was not able to discuss about the formation and disappearance process of thermal stratification.

Wind action and thermal convection caused a slope of the interface. Spatial slope can be calculated from difference of mixed layer depth by:

$$
S_{x}=d h / d x
$$

where $d h$ is difference (m) in mixed layer depth, and $d x$ is distances $(\mathrm{m})$.

Another equation for definition of the slope of the interface $S_{H}$ was given by Ford and Johnson (Martin and McCutcheon 1998) as:

$$
S_{H}=\frac{u_{*_{w}}^{2}}{\left(g \frac{\rho_{w}}{\Delta \rho}\right) H}=R_{i H}^{-1}
$$

where $\Delta \rho$ is difference of density between upper and lower layers of the interface or thermocline $\left(\mathrm{kg} / \mathrm{m}^{3}\right) ; H$ is
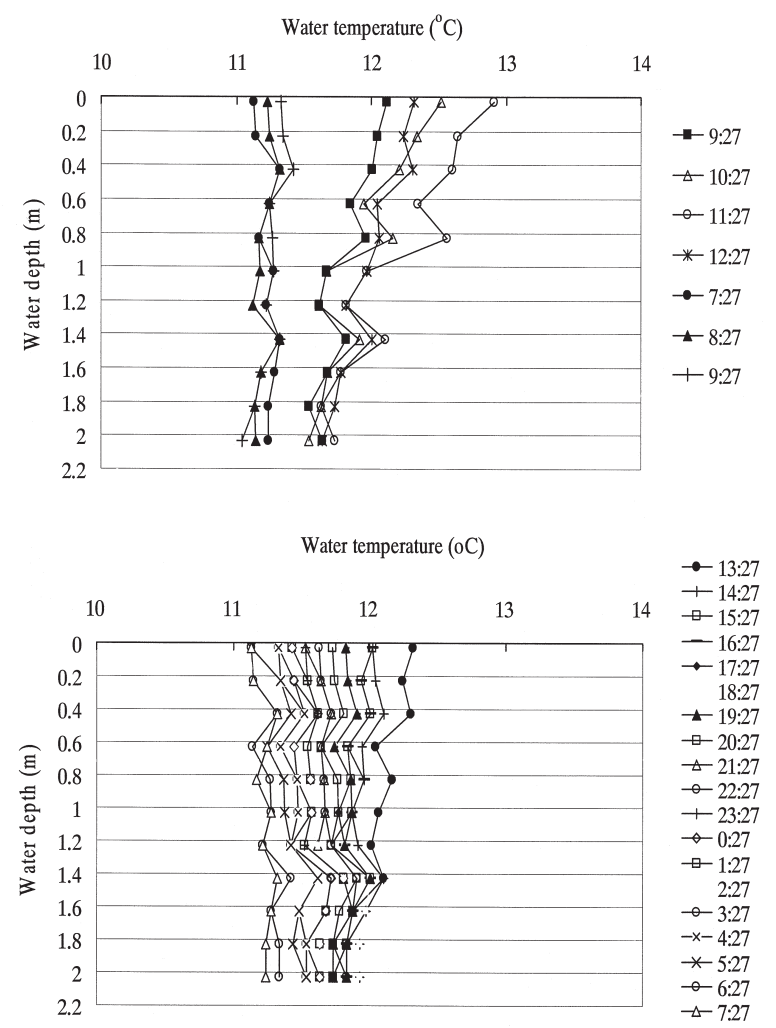

Fig. 5. Temporal variation of vertical distribution of water temperaturea at $\mathrm{S} 2\left(2^{\text {nd }}\right.$. Obs. $)$ 
the average depth of the lake $(\mathrm{m}) ; R_{i H}$ is Richardson number calculated with $H, R_{i H}$ could be calculated by:

$$
R_{i H}=\frac{\Delta \rho g H}{\rho_{w} u_{*_{w}}^{2}}
$$

Normally, it is easy to measure total depth of the lake while the mixed layer depth is difficult to define exactly. Therefore, equation (13) could be used for calculation of the interface slope in a specific scale of the lake with a modifying coefficient $\beta<1$ as:

$$
S_{x}=\beta R_{i H}^{-1}
$$

Fig. 6 shows relationships between $R_{i H}$ and interface slopes $S_{x}$. Result in this figure presented that in case of Lake Shikinawa, $\beta$ could be chosen in a range from 0.1 to 0.8 . When considering equations (19) and (20), this coefficient might be defined relatively to ratio $h / H$. Moreover, $\beta$ depends on scale of the lake, ratio $H / L$, with $L$ is the length of the lake, that is, Wedderburn number.

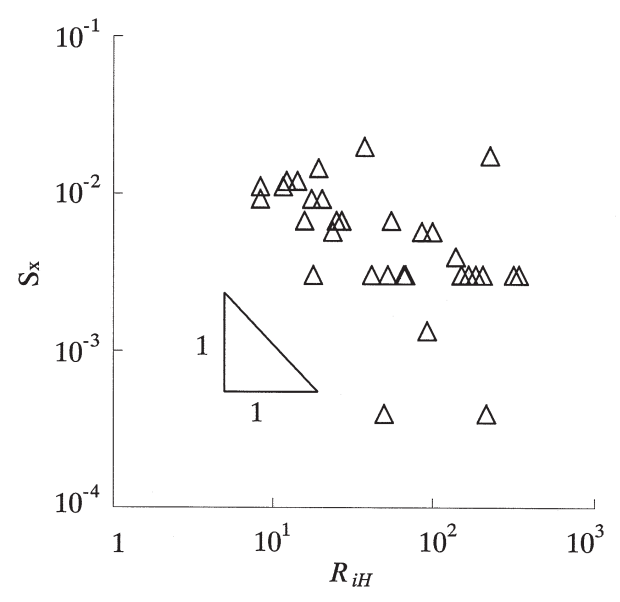

Fig. 6. Relationship between Richardson number and interface slope.

Temporal variation of mixed layer depth, or entrainment velocity, can be obtained by:

$$
u_{e}=d h / d t
$$

where $u_{e}$ is entrainment velocity $(\mathrm{m} / \mathrm{s}) ; d t$ is time step (s).

The entrainment rate $E_{w}$ is a ratio of entrainment velocity and water friction velocity as:

$$
E_{w}=u_{e} / \sigma=u_{e} / u_{*_{w}}
$$

Richardson number, which illustrated stability of thermal stratification, can be defined by:

$$
R_{i w}=\frac{\Delta \rho g h}{\rho_{w} u_{*_{w}}^{2}}
$$

where $R_{i w}$ is Richardson number due to water friction velocity, which represented ratio of buoyancy to shear force (Charpa 1998); $h$ is mixed layer depth (m).

The entrainment rate $E_{f}$ is a ratio of entrainment velocity and thermal convection as:

$$
E_{f}=u_{e} / \sigma=u_{e} / u_{f}
$$

Richardson number due to thermal convection $\left(R_{i f}\right)$ can be obtained similarly to equation (13), with replacement of $u_{*_{a}}$ by $u_{f}$ :

$$
R_{i f}=\frac{\Delta \rho g h}{\rho_{w} u_{f}^{2}}
$$

Fig. 7 shows the relationship between the entrainment rate and the Richardson number, in two cases of wind mixing and thermal convection.

Mori et al. (1989) in his research based on experimental study has found that the entrainment rate law was divided into two regions by the values of overall Richardson numbers, $E \propto R_{i}^{-1}$ when $R_{i}>100$ and $E \propto R_{i}^{-3 / 2}$ when $R_{i}<100$.

Results calculated during wind mixing periods (Fig. 7.a) showed a good agreement with above conclusion in case of $R_{i}<100$, but it was strange when $R_{i}>100$. For result obtained when estimating thermal convection component (Fig. 7.b), it was difficult to find out a general law for relationship between entrainment rate and Richardson number. This phenomenon might be caused by quality of vertical water temperature, which was observed in a large interval of $0.2 \mathrm{~m}$. Moreover, there was

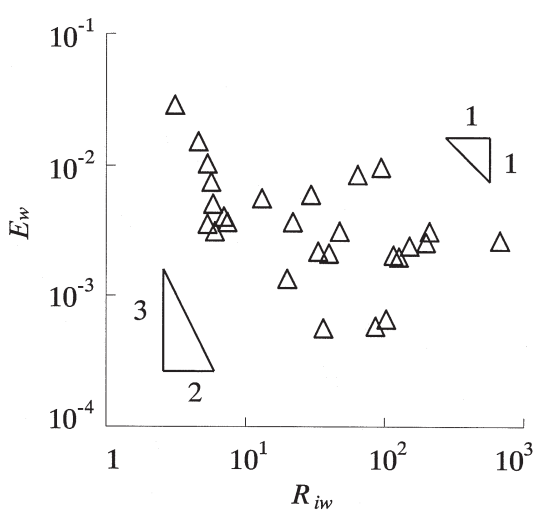

(a)

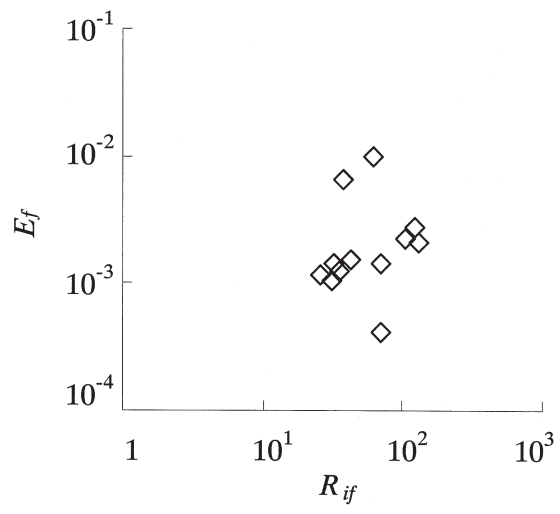

(b)

Fig. 7. Entrainment rates plotted logarithmically as a function of Richardson numbers. 
no reference which estimates this relationship of thermal convection.

In addition, using the equations (6) and (7) mixing layer depth $h$ and $h / H$ were found, the results were shown in Fig. 8. Figs. 8(b), (c) calculated friction velocity $u_{*}$, the values of layer-averaged Brunt-Vaisala frequency being made to change, respectively. From the results of the field observation, $N^{2}=0.0038$ in Fig. 8(c), $u_{*}=0.32$ was fixed in Fig. 8(b). The minimum value of $0.7 \mathrm{~cm}$ of friction velocity is necessary to reach all-layer
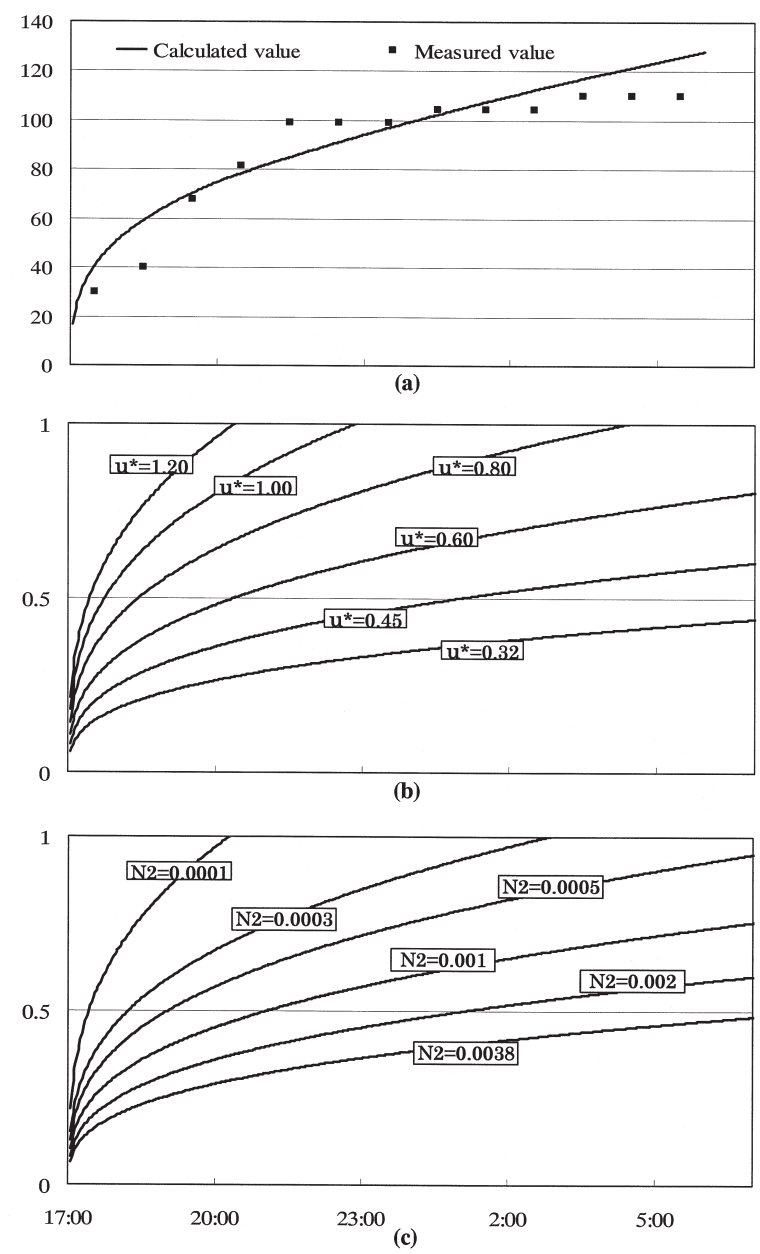

Fig. 8. (a) (b) (c) The temporal change of $h / H$ and mixing layer depth $h$.

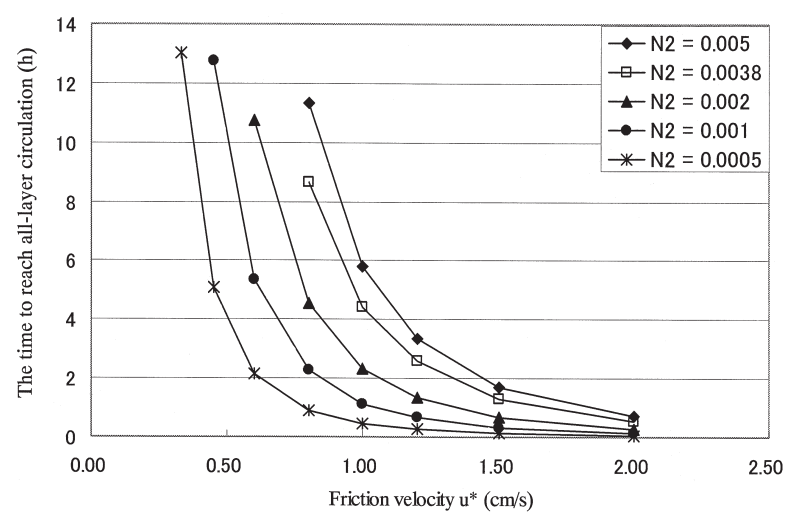

Fig. 9. The time to reach all-layer circulation. circulation by the morning, if Brunt-Vaisala frequency is 0.0005 , also in the wind velocity condition of this time, being able to reach all-layer circulation was estimated in the Shikinawa Lake in Summer. Fig. 9 summarized the time to reach all-layer circulation, impacts that water friction velocity and the early stratification state affects the development speed of mixing layer.

\section{CONCLUSIONS}

Based on field observation, the processes of formation and disappearance of thermal stratification against disturbance in a shallow closed water body was investigated. Some conclusions have been drawn as follows :

1. Under the case of the action of only thermal disturbance, in the heat receiving period, water temperature differences in vertical direction occurred, thermal stratification developed. Stratification was not broken by thermal convection based on radiation cooling at night, the inhibition to vertical transportation occurred, it caused the state of poor oxygen in low layer.

2. In the case of existence of floating-leaved plants, heating caused by solar radiation in daytime, or radiation cooling at night was inhibited, the processes of rising and falling water temperature were slow compared to other observed points.

3. In August of observation, increment rate of mixing layer thickness due to wind action was four times higher than that caused by thermal convection.

4. Results concluded from this research are very useful for understanding and simulating thermal regime inside a closed, small, and shallow water body, including surface exchange at the air-water interface, mixing, convection and stratifying process in lake's circulation.

\section{ACKNOWLEDGEMENT}

The authors would like to thank very much to the undergraduate and graduate students at Laboratory of Bioproduction and Environmental Information Sciences, Graduate School of Bioresource and Bioenvironmental Sciences, Kyushu University, for their co-operations in the field observations. We also would like to express the gratefulness to Laboratory of Irrigation and Water Utilization, Laboratory of Drainage and Water Environment, Graduate School of Bioresource and Bioenvironmental Sciences, Kyushu University, for their support of some experimental tools.

\section{REFERENCES}

Charpa, S. C. 1998 Surface water quality modeling. McGrawHill, pp. 560-589

Lap, B. Q., K. Mori and Y. Hirai 2006 Some primary characteristics of water quality in a closed water body in Sasaguri, Fukuoka Prefecture, Japan. J. Fac. Agr., Kyushu Univ., 51(2): 315-321 Lap, B. Q. and K. Mori 2007 A two-dimensional numerical mode of wind-induced flow and water quality in closed water bodies. Paddy Water Environ., 5(1): 29-40 
Martin, J. L and S. C. McCutcheon 1998 Hydrodynamic and Transport for Water Quality modeling. Lewis Publisher, pp. 355-420

Mori, K., Tohara, Y and Kato, O. 1989 Experiment study on entrainment rate of density interface due to a wind induced current. Trans. of JSIDRE., pp. 85-93
Mori, K., S. Shikasho and K. Hiramatsu 2001 Daily cycle variation of dissolved oxygen in a shallow closed water body. Fishery engineering 38(1): 53-59

Mori, K., S. Shikasho and K. Hiramatsu 2001 Wind-induced flow in a closed-water area with discrete wind shear. Fisheries Eng 37(3): 195-201 